\title{
Training family care givers of people with dementia to think in a more clinical manner decreased depression and the sense of burden
}

\author{
Hepburn KW,Tornatore J, Center B, et al. Dementia family caregiver training: affecting beliefs about caregiving and \\ caregiver outcomes.J Am Geriatr Soc 2001 Apr;49:450-7.

\section{QUESTION: Does training family care givers of individuals with dementia to view their role in a more clinical manner reduce adverse events associated with care giving?}

\section{Design}

Randomised (allocation not concealed), blinded \{outcome assessor $\}^{*}$, controlled trial with follow up 3 months after the intervention.

\section{Setting}

Minneapolis, Minnesota, USA.

\section{Participants}

117 family care giver - care receiver dyads, which consisted of primary informal care givers (mean age 77 y, $56 \%$ men; $94 \%$ were spouses or parents) of relatives with dementia that had not progressed beyond stage $7 \mathrm{~b}$ of the Functional Assessment Staging (mean age $65 \mathrm{y}$, $70 \%$ women) who were living in community settings (ie, not nursing homes). 94 dyads $(80 \%)$ were included in the analysis.

\section{Intervention}

72 care givers accompanied by $\geqslant 1$ family member were allocated to the intervention and given group training in 7 weekly, 2 hour workshops based on a stress and coping theoretical model, by a multidisciplinary team including a nurse, educator, family therapist, and occupational therapist. Participants were told that the training was similar to that which a clinician or nurse's aid would receive, were given reading assignments, and instructed to try to implement strategies learned in the workshop. Training included information on dementia and its progressive effect on cognitive functioning; strategy development for managing daily life and behaviour; emphasis on the care giver's role in assuring security and helping the care receiver to enjoy life; development of clinical care giving beliefs and strategies such as viewing a situation from a distance, dealing with care giving situations, and developing a strong belief that care givers should care for their own needs as well as the care receiver's; and presentation and reinforcement of the care giver's newly acquired skills. 45 care givers were allocated to a waiting list.

\section{Main outcome measures}

Care giver behaviour change scores on the Beliefs about Caregiving Scale (BACS), the Revised Memory and Behavior Problem Checklist, Revised Zarit Burden Scale, and the Center for Epidemiologic Studies Depression Scale.

\section{Main results}

At 3 months after the intervention, care givers in the treatment group were more nurturing than care givers in the control group ( $\mathrm{p}=0.025)$, had fewer negative reactions to care receivers' behaviour problems $(\mathrm{p}=0.019)$, and had lower levels of depression $(\mathrm{p}=0.04)$ and feelings of burden $(\mathrm{p}=0.051)$. Hierarchical linear regression showed that positive improvements in monitoring were associated with less depression $(\mathrm{p}=0.04)$ and burden $(\mathrm{p}=0.001)$, as were positive improvements in nurturing beliefs ( $\mathrm{p}=0.007$ and $\mathrm{p}=0.019$, respectively).

\section{Conclusion}

Training family care givers of individuals with dementia to approach their role in a more clinical and strategic manner increased their ability to nurture and handle behaviour problems, and reduced levels of depression and sense of burden.

*Information provided by author.

\section{COMMENTARY}

Caring for the elderly has taken on unprecedented importance in an aging population where greater expectations are being placed on informal care givers who experience physical, emotional, social, and financial consequences. ${ }^{1}$ Little is known, however, about how to effectively support informal care givers. ${ }^{23}$ The study by Hepburn et al makes an important contribution by showing the effectiveness of a role training intervention in ameliorating the adverse outcomes associated with care giving.

The participants were all from one community in the upper midwest US Consequently, findings should only be generalised to those who are help seekers with similar ethnicity, income, and education.

Interpreting the findings of this study is difficult. Little is known about the clinical significance of shifts in scales measuring concepts such as depression or burden. The care receiver outcome (frequency of behaviour problems 3 months after treatment) did not differ between the intervention and wait list groups. This could be because the sample size was not large enough to detect a difference, the scale was unable to measure small increments of change, or because the study was short in relation to the median life expectancy of 7-10 years from the time of diagnosis of Alzheimer's disease.

Community nurses, who often work in partnership with informal care givers, are in an ideal position to offer or recommend family care giving training to interested care givers who may be struggling to maintain their loved one at home. Such a programme would assist informal care givers in understanding the disease process of dementia, recognising their own limitations in caring for their loved ones, and reducing their adverse outcomes.

Dorothy Forbes, RN, PhD Associate Professor, College of Nursing University of Saskatchewan Saskatoon, Saskatchewan, Canada

1 Fast JE, Forbes DA, Keating NC. Contributions and needs of informal elder care providers in Canada: evidence from Statistics Canada's 1996 General Social Survey on social supports. Edmonton, Alberta: Health Promotion and Programs Branch, Health Canada, 1999.

2 Forbes DA. Strategies for managing the behavioural symptomatology associated with dementia of the Alzheimer type: a systematic overview. Can J Nurs Res 1998;30:67-86.

3 Thompson C, Spilsbury K. Support for carers of people with Alzheimer's type dementia. Cochrane Database Syst Rev 2001;(2):CD000454. 